\title{
The seismic signatures of the 2009 Shiaolin landslide in Taiwan
}

\author{
Z. Feng \\ Department of Soil and Water Conservation, National Chung Hsing University, Taichung 402, Taiwan \\ Received: 16 November 2010 - Revised: 27 January 2011 - Accepted: 25 April 2011 - Published: 25 May 2011
}

\begin{abstract}
The Shiaolin landslide occurred on 9 August 2009 after Typhoon Morakot struck Taiwan, claiming over 400 lives. The seismic signals produced by the landslide were recorded by broadband seismic stations in Taiwan. The time-frequency spectra for these signals were obtained by the Hilbert-Huang transform (HHT) and were analyzed to obtain the seismic characteristics of the landslide. Empirical mode decomposition (EMD) was applied to differentiate weak surface-wave signals from noise and to estimate the surface-wave velocities in the region. The surface-wave velocities were estimated using the fifth intrinsic mode function (IMF 5) obtained from the EMD. The spectra of the earthquake data were compared. The main frequency content of the seismic waves caused by the Shiaolin landslide were in the range of 0.5 to $1.5 \mathrm{~Hz}$. This frequency range is smaller than the frequency ranges of other earthquakes. The spectral analysis of surface waves (SASW) method is suggested for characterizing the shear-wave velocities of the strata in the region.
\end{abstract}

\section{Introduction}

\subsection{The Shiaolin landslide}

Shiaolin village, located in Southern Taiwan (Fig. 1a), was destroyed after a landslide and natural dam breach during Typhoon Morakot. The catastrophic landslide occurred at 06:16 a.m. LT on 9 August 2009, Taiwan. The landslide dam blocked the Chishan River (Fig. 1b) and covered approximately half of the Shiaolin village. The landslide dam was subsequently breached due to flooding, and the surge waves destroyed the remaining half of the Shiaolin village. This

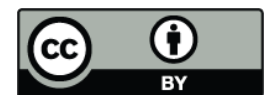

Correspondence to: Z. Feng

(tonyfeng@nchu.edu.tw) catastrophic landslide claimed over 400 lives. The Shiaolin landslide was primarily triggered by the tremendous amount of precipitation that occurred over a short period of time (approximately $1676 \mathrm{~mm}$ over three days). The landslide was deep-seated and occurred on a dipping slope of shale, mudstone, and sandstone. The material fell approximately $830 \mathrm{~m}$ from the head scarp (Tsou et al., 2011). The landslide was estimated to be 25 million $\mathrm{m}^{3}$ in volume and traveled approximately $2.83 \mathrm{~km}$ (Fig. 1a), with an average velocity of 20.4 to $33.7 \mathrm{~m} \mathrm{~s}^{-1}$ (Tsou et al., 2011). The affected area was approximately 252 hectares (Chen and $\mathrm{Wu}, 2009 \mathrm{a}$ ). The landslide dam was approximately $53 \mathrm{~m}$ tall, $350 \mathrm{~m}$ wide, and $600 \mathrm{~m}$ long. The volume of the dam lake was about 19.5 million $\mathrm{m}^{3}$, and the area of the dammed lake was approximately 92 hectares (Chen and $\mathrm{Wu}, 2009 \mathrm{~b}$ ). The surge waves following the dam break arrived at Jiasian (approximately $12 \mathrm{~km}$ downstream) at 08:03 a.m. LT and at the Shanlin stream station (approximately $30.5 \mathrm{~km}$ downstream) at 08:40 a.m. LT on 9 August 2009 (Feng, 2011). Note that all of the times referenced in this paper are local time and offset from UTC by $+8 \mathrm{~h}$.

\subsection{The seismology of landslides}

Seismic signals generated by landslides can be recorded and analyzed to observe the seismic and geologic aspects and characteristics of a landslide (Berrocal et al., 1978; Suriñach et al., 2005). Experimental man-made rockfall-induced seismic signals have been studied to detect rockfall size and the locations of the impacts (Vilajosana et al., 2008). The seismic method has also been applied to illustrate the seismic signature of pyroclastic flows (De Angelis et al, 2007), showing that seismology can be useful in characterizing hazardous processes such as landslides.

The sliding mass of the Shiaolin landslide had a surface magnitude equivalent to an $M_{\mathrm{S}}=4.6$ seismic event (C.H. Lin, personal communications, 2010). The long-period

Published by Copernicus Publications on behalf of the European Geosciences Union. 
seismic signals were recorded by most of the Broadband Array in Taiwan for Seismology (BATS) network and by the F-net in Japan (Lin et al., 2010). Lin et al. (2010) have identified the location of the Shiaolin landslide using long-period (20-50 s or $0.02-0.05 \mathrm{~Hz}$ ) band-pass filtered BATS records. They also estimated the source locations of 51 other landslide events from their long-period BATS signals, including submarine slumps that occurred during the typhoon. The author discovered that the seismic signals from the dam-break surge waves were also captured by the Jiasian SGSB broadband station of the BATS network. The characteristics of the seismic signals caused by the surge waves indicated that the landslide dam breached $1 \mathrm{~h}, 24 \mathrm{~min}$ after the Shiaolin landslide occurred (Feng, 2011).

\subsection{Purposes of this study}

This study employs the vertical components of six broadband BATS stations near Shiaolin (Fig. 2) and focuses mainly on the characteristics of the seismic waves generated by the Shiaolin landslide. These signals have relatively shorter periods and higher frequency ranges $(0.5-5 \mathrm{~Hz})$ than those used in Lin et al. (2010).

The empirical mode decomposition (EMD) and HilbertHuang transform (HHT) (Huang et al., 1998) were employed to explore the characteristics of the seismic signatures of the Shiaolin landslide. The surface-wave velocities were estimated using the intrinsic mode functions (IMFs) from the EMD. The earthquake data from the free-field strong-motion seismometers at two of the broadband stations were also compared. A potential application of the spectral analysis of surface waves (SASW) method was also explored.

\section{Materials and methods}

\subsection{The broadband signals}

Information about the broadband stations is listed in Table 1, including their azimuths and distances from Shiaolin. The seismic signals from the six broadband stations for the 06:10 to $06: 25$ a.m. LT time interval on 9 August were acquired. Although three components of the waveform data (Z, N-S, and $\mathrm{E}-\mathrm{W}$ ) were available, only the vertical components (the Z-direction) were used in this analysis. These data were used to estimate arrival times and surface-wave velocities from the Rayleigh waves. To determine the characteristics of the seismic signals from the landslide, the time-frequency spectra from these stations were calculated using the HHT. The propagation of landslide-induced seismic waves may be influenced by surface topography. The topographic profiles from Shiaolin to the stations are plotted in Fig. 3.

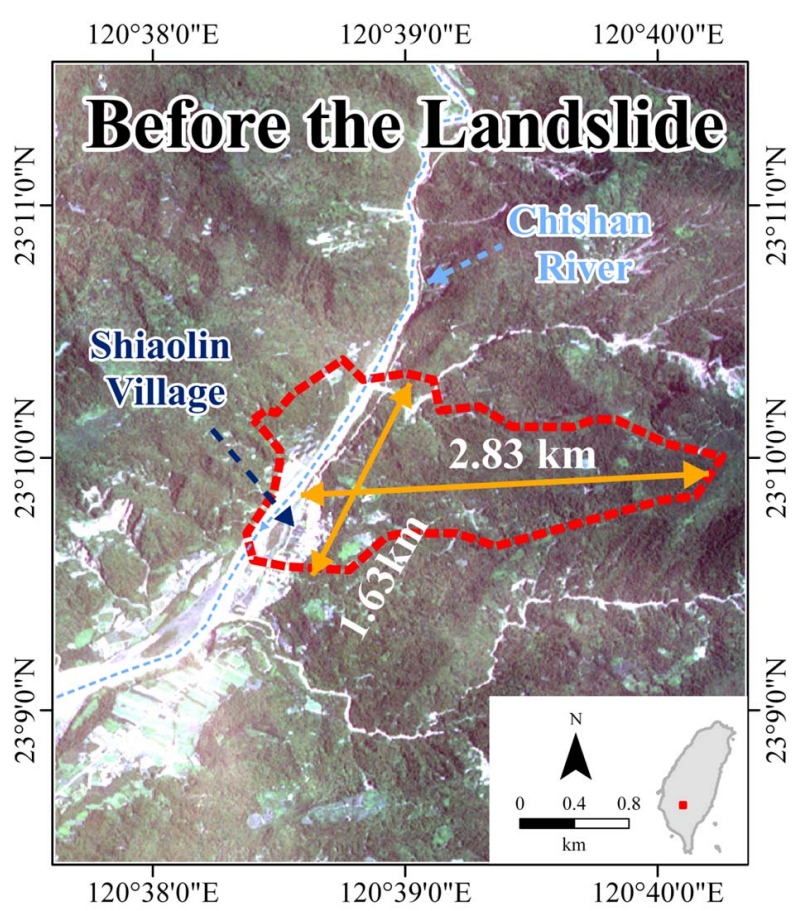

(a)

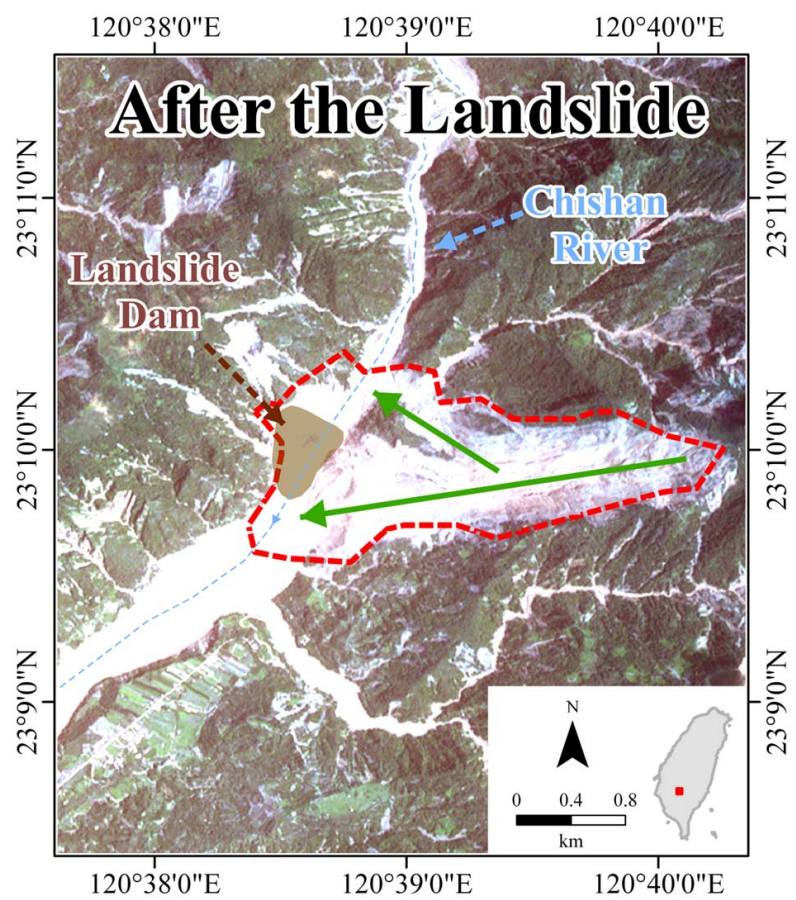

(b)

Fig. 1. (a) The Shiaolin village and Chishan River prior to the Shiaolin landslide (SPOT image from 22 June 2008). The red dotted line indicates the Shiaolin landslide zone. (b) The landslide area and the landslide dam after the Shiaolin landslide, 9 August 2009 (SPOT image 24 August 2009). The red dotted line indicates the Shiaolin landslide zone, and the green arrows indicate the sliding directions. 


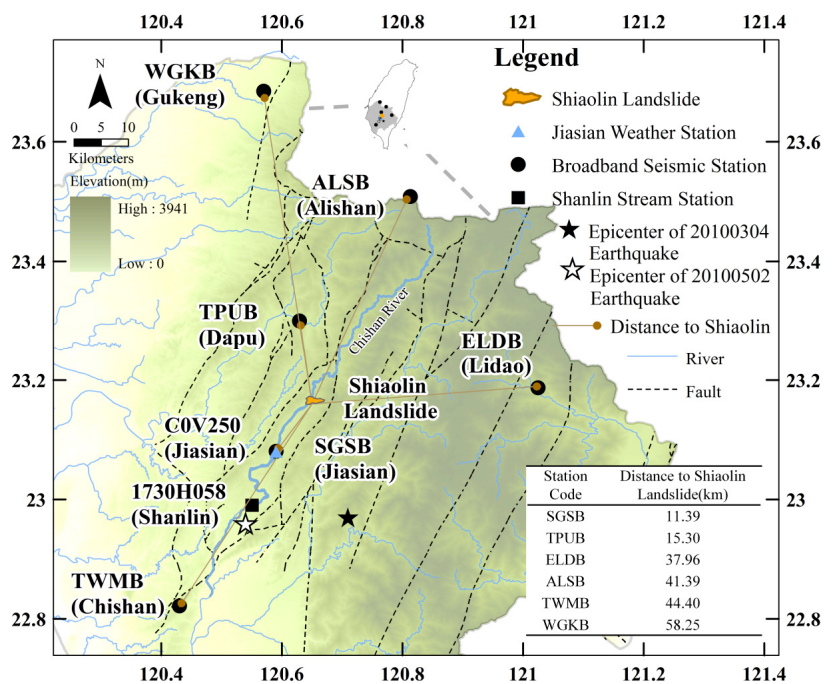

Fig. 2. The locations of the six broadband seismic stations, the Jiasian rainfall gauge station (COV250), and the Shanlin stream gauge station (1730H058).

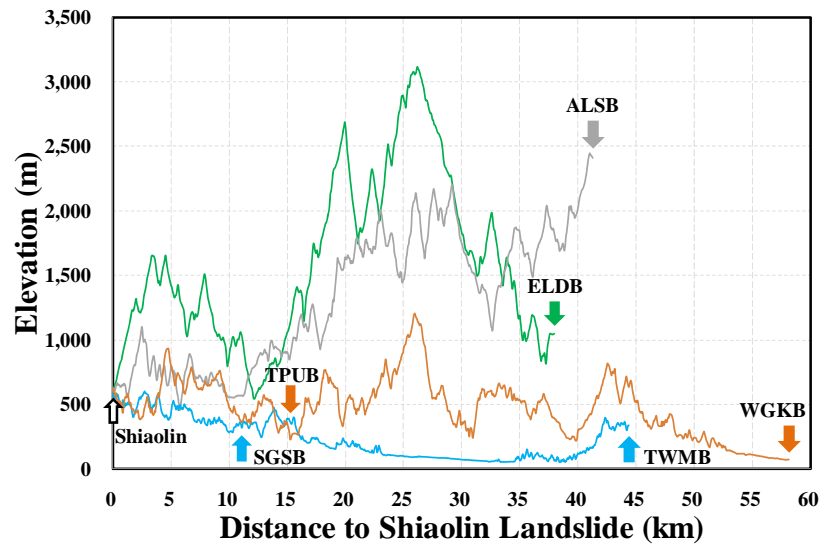

Fig. 3. The topographical profiles from Shiaolin to the broadband stations.

\subsection{Geology of the Shiaolin-Jiasian-Chishan region}

Figure 4 illustrates the geological structures and stratigraphy of the study area. The Shiaolin-Jiasian-Chishan region is located in the southern part of the Western Foothills of Taiwan. The region is mainly sandstone, mudstone, conglomerate, and interlayered sandstone and shale. They are of the Quaternary period and the Pliocene and Miocene epochs (Central Geological Survey, 2010).

According to Chen and Liu (2006), the Neiying Fault runs across this area with a $10^{\circ} \mathrm{N}-30^{\circ} \mathrm{E}$ orientation that is generally parallel to the strike of the local stratigraphy. It is an approximately 40-km-long sinistral reverse fault. The exposed formations in the hanging-wall area of the Neiying Fault are mainly the Changchikeng Formation and the Tan-

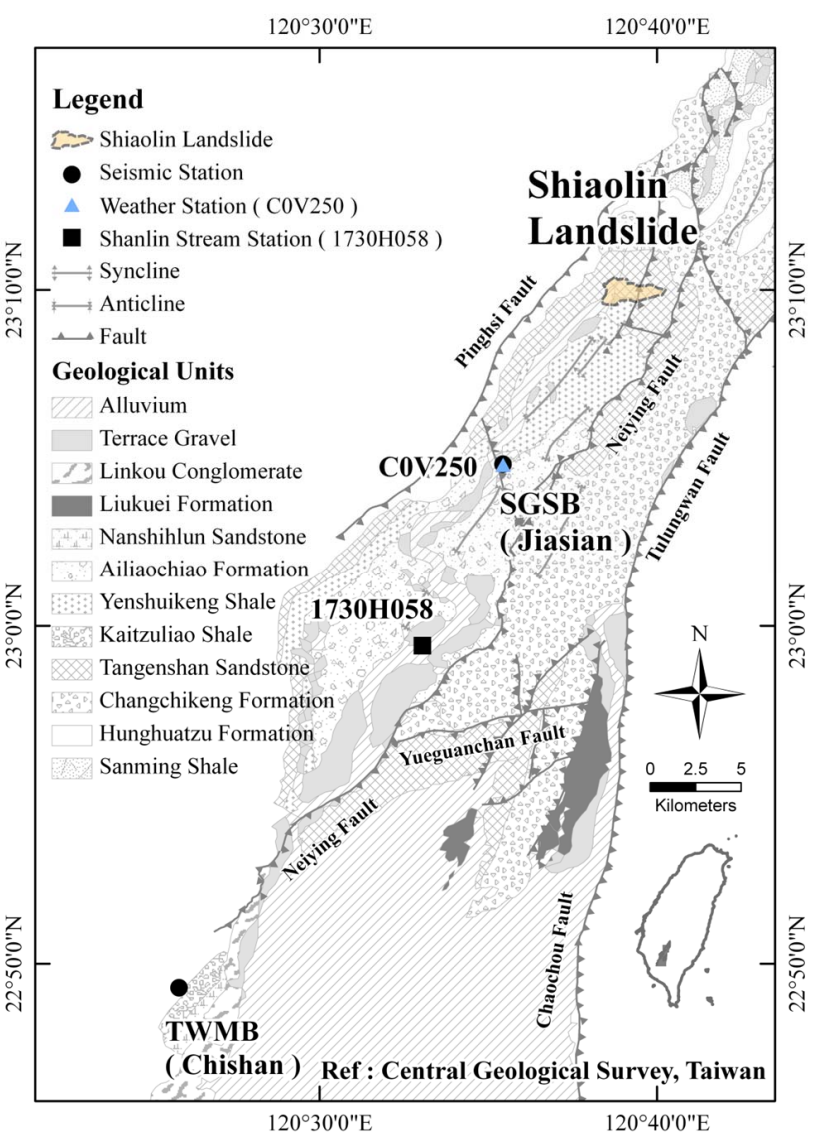

Fig. 4. The geological map of the region containing Shiaolin, Jiasian, and Chishan (Modified from Tsou et al., 2011).

genshan Sandstone, which are from the late Miocene. In the footwall area of the Neiying Fault, the formations are primarily the Pliocene and Pleistocene Yenshuikeng Shale and Ailiaochiao Formations. The Changchikeng Formation and Ailiaochiao Formation consist predominantly of shale, as indicated in Keng (1967)

The locations of the SGSB seismic station in Jiasian and the TWMB seismic station in Chishan, along with the C0V250 weather station in Jiasian, are shown in Fig. 4. Shiaolin village, SGSB and TWMB are located in the footwall of the Neiying Fault and are aligned in an almost straight line that is subparallel to the strike of the stratigraphy in this area.

\subsection{Earthquake data from the free-field strong-motion stations}

The earthquake records of the free-field, strong-motion stations and broadband stations at Jiasian and Chishan were compared. The earthquake records include the $M_{\mathrm{S}}=$ 6.4 earthquake (4 March 2010; $120.71^{\circ} \mathrm{E}, 22.97^{\circ} \mathrm{N}$ ) near Shiaolin and Jiasian, the $M_{\mathrm{S}}=7.3$ Chi-Chi earthquake (21 September $\left.1999 ; 120.82^{\circ} \mathrm{E}, 23.85^{\circ} \mathrm{N}\right)$, and the $M_{\mathrm{S}}=6.4$ 
Table 1. Station information and the distances to Shiaolin.

\begin{tabular}{llllllll}
\hline & $\begin{array}{l}\text { Station } \\
\text { Code }\end{array}$ & Location & $\begin{array}{l}\text { Longitude, } \\
\mathrm{E}\end{array}$ & $\begin{array}{l}\text { Latitude, } \\
\mathrm{N}\end{array}$ & $\begin{array}{l}\text { Elevation } \\
(\mathrm{m})\end{array}$ & $\begin{array}{l}\text { Distance to } \\
\text { Shiaolin, } \\
\Delta(\mathrm{km})\end{array}$ & $\begin{array}{l}\text { Shiaolin-to } \\
\text {-station Azimuth } \\
\text { (degrees) }\end{array}$ \\
\hline $\begin{array}{l}\text { Shiaolin } \\
\text { Landslide }\end{array}$ & - & Shiaolin & 120.65 & 23.16 & 345 & - & - \\
\hline $\begin{array}{l}\text { Broadband } \\
\text { seismic }\end{array}$ & SGSB & Jiasian & 120.59 & 23.08 & 278 & 11.39 & 215.54 \\
stations & TPUB & Dapu & 120.63 & 23.30 & 370 & 15.30 & 350.30 \\
& ELDB & Lidao & 121.03 & 23.19 & 1040 & 37.96 & 86.26 \\
& ALSB & Alishan & 120.81 & 23.51 & 2413 & 41.39 & 23.12 \\
& TWMB & Chishan & 120.43 & 22.82 & 340 & 44.40 & 211.41 \\
& WGKB & Gukeng & 120.57 & 23.68 & 75 & 58.25 & 351.59 \\
\hline $\begin{array}{l}\text { Jiasian rainfall } \\
\text { gauge station }\end{array}$ & C0V250 & Jiasian & 120.58 & 23.08 & 270 & 11.80 & 215.37 \\
\hline $\begin{array}{l}\text { Shanlin stream } \\
\text { gauge station }\end{array}$ & 1730H058 & Shanlin & 120.54 & 22.99 & 130 & 22.05 & 209.14 \\
\hline
\end{tabular}

* River length from the station to the Shiaolin landslide dam.

Table 2. The percentage powers of the IMFs at the SGSB, TPUB, and TWMB stations.

\begin{tabular}{llll}
\hline IMF & $\begin{array}{l}\text { Percentage } \\
\text { power }(\%) \\
\text { at SGSB }\end{array}$ & $\begin{array}{l}\text { Percentage } \\
\text { power }(\%) \\
\text { at TPUB }\end{array}$ & $\begin{array}{l}\text { Percentage } \\
\text { power }(\%) \\
\text { at TWMB }\end{array}$ \\
\hline IMF 1 & 0.76 & 5.41 & 0.18 \\
IMF 2 & 2.15 & 1.23 & 0.10 \\
IMF 3 & 2.64 & 1.36 & 0.04 \\
IMF 4 & 3.86 & 2.75 & 0.13 \\
IMF 5 & 38.84 & 44.93 & 0.90 \\
IMF 6 & 15.54 & 17.14 & 10.06 \\
IMF 7 & 29.48 & 21.28 & 74.05 \\
IMF 8 & 4.93 & 4.76 & 12.20 \\
IMF 9 & 0.74 & 0.48 & 1.43 \\
Sum of 10 14 IMFs & 1.06 & 0.65 & 0.9 \\
\hline
\end{tabular}

Note: These percentage powers for the SGSB and TWMB IMFs were calculated using signals from a 15-min duration (from 06:10 to 06:25) on 9 August 2009. For the TPUB station, a 5-min duration (from 06:15 to 06:20 a.m. LT) was used.

Jiayi earthquake (22 October $\left.1999 ; 120.42^{\circ} \mathrm{E}, 23.52^{\circ} \mathrm{N}\right)$. Records from an $M_{\mathrm{S}}=4.57$ earthquake (2 May 2010; $120.54^{\circ} \mathrm{E}, 22.96^{\circ} \mathrm{N}$ ) were acquired from the SGSB and TWMB stations to compare with the equivalent-magnitude $\left(M_{\mathrm{S}}=4.6\right)$ signal generated by the Shiaolin landslide. The differences in the time-frequency spectra of the signals caused by the Shiaolin landslide and the earthquakes were then compared.

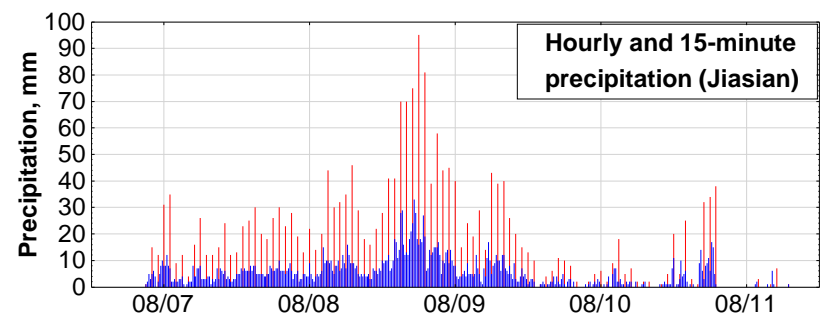

Fig. 5. The hourly and quarter-hourly precipitation levels at the Jiasian rainfall gauge station (COV250) during Typhoon Morakot (7-11 August 2009).

\subsection{Precipitation and the water level of the Chishan River during Typhoon Morakot}

The typhoon precipitation data from the Jiasian Weather Station (COV250), which were taken at one-minute intervals, were acquired. The hourly and quarter-hourly precipitation levels are shown in Fig. 5. The cumulative precipitation had reached $1676 \mathrm{~mm}$ by the time the Shiaolin landslide occurred (Tsou et al., 2011). The location of C0V250 is about $12 \mathrm{~km}$ SSW of Shiaolin. It is close to the SGSB seismic station; however, the high-intensity precipitation did not perturb the seismic signals from the SGSB, as indicated by Feng (2011).

The Shanlin Stream station (173H058) is located approximately $30.5 \mathrm{~km} \mathrm{SSW}$ from Shiaolin, downstream along the Chishan River. It recorded water-level variations at tenminute intervals. The water levels measured at the Shanlin station during Typhoon Morakot are shown in Fig. 6a. The decrease in the water level at the arrow labeled K in Fig. 6a is related to the breaking of a dike near Jiasian, as noted by 

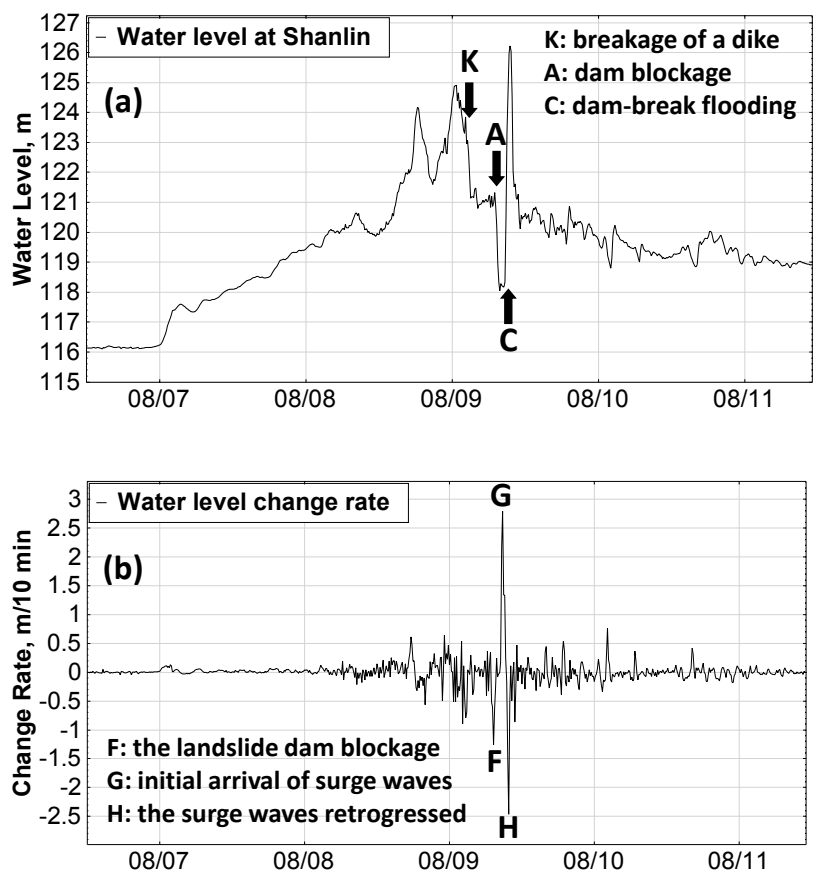

Fig. 6. (a) The water levels (stages) measured at the Shanlin stream gauge station (1730H058) from 06:00 to 11:00 a.m. LT on 9 August 2009, with a 10-min sampling frequency. (b) The rate of change in the water level is in units of $\mathrm{m} 10 \mathrm{~min}$.

Chen and $\mathrm{Wu}(2009 \mathrm{~b})$. The decreasing water level labeled A is due to the landslide dam blocking. The suddenly increasing water level labeled $\mathrm{C}$ is caused by the surge waves from the breaking of the dam.

The water-level curve of the Shanlin in Fig. 6a was differentiated to obtain the rate of the water-level change $(1 \mathrm{~m}$ per $10 \mathrm{~min}$ ), as shown in Fig. $6 \mathrm{~b}$. When the rate of change is close to zero, the water level remains approximately constant. A positive rate represents a rising water level; a negative rate represents a falling water level. The rate of change in the water level due to the landslide dam blockage was $1.3 \mathrm{~m}$ per $10 \mathrm{~min}$ at 07:20 (time-point $\mathrm{F})$. The highest rate $(2.8 \mathrm{~m}$ per $10 \mathrm{~min}$ ) was observed at 08:50 (time-point $\mathrm{G}$ ) during the initial surge of waves from the dam break. The water level dropped quickly $(-2.5 \mathrm{~m}$ per $10 \mathrm{~min}$ ) at 09:50 (time-point $\mathrm{H}$ ) when the surge of waves retrogressed.

\subsection{Empirical mode decomposition and the Hilbert-Huang transform}

The HHT developed by Huang et al. (1998) includes EMD and the Hilbert transform. The EMD process can decompose a signal into a set of intrinsic mode functions (IMFs). This method is powerful because of its adaptability and efficiency. It is useful for analyzing nonlinear and nonstationary signals. The EMD method decomposes signals into many IMFs with a low-frequency residual. Then, using the Hilbert transform,
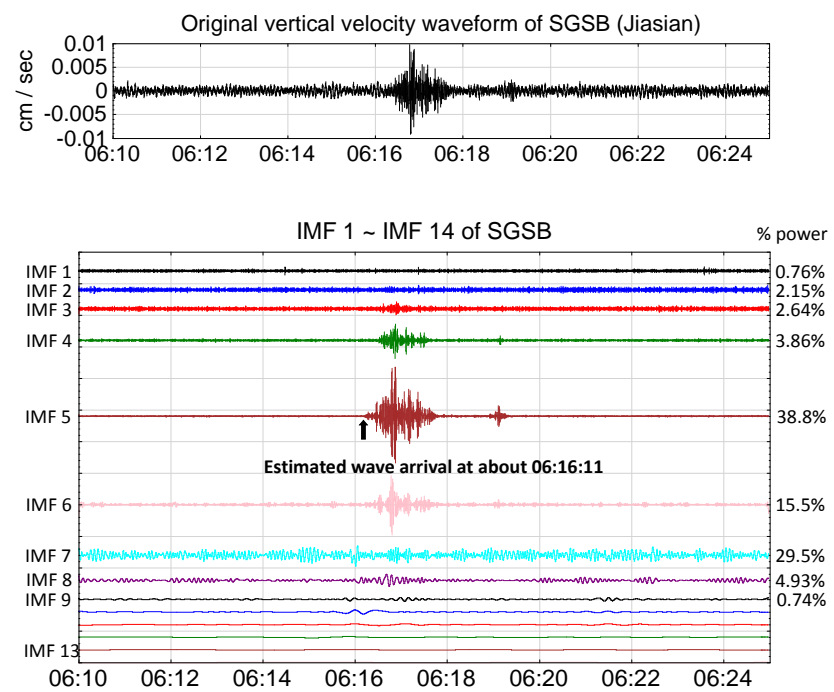

Fig. 7. IMFs $1-14$ of the vertical velocity from the Jiasian SGSB station (06:10 to 06:25 a.m. LT, 9 August 2009).

each of the IMFs can be transformed to obtain their instantaneous frequencies as a function of time. Subsequently, the time-frequency energy spectra of the signals can be obtained. The seismic characteristics can be interpreted by examining the frequency contents in the time domain. For details of the EMD and HHT methods, please see Huang et al. (1998). EMD and the HHT have been applied to many areas of geophysics, including seismic, atmospheric, climatic, groundwater, sea-wave, and soil-science studies (Huang and $\mathrm{Wu}$, 2008; Crockett et al., 2010; Crockett and Gillmore, 2010). The Visual Signal software (AnCAD, Inc., 2010) was used in this study to perform EMD and the HHT.

EMD was employed to "sift" the time series signals of the broadband stations and to "separate" the frequency ranges of the signals caused by the Shiaolin landslide. By obtaining the time-frequency-energy spectra of the broadband signals using the HHT, the characteristics of the seismic data could be more clearly observed and compared.

\section{Results and discussion}

\subsection{EMD of the landslide signals from the broadband stations}

SGSB is the nearest station to the Shiaolin Landslide; therefore, the seismic signals of the landslide were clearest there. The 14 IMFs resulting from the EMD processing of the 15min vertical-component velocity signal are shown in Fig. 7. Table 2 lists the percentage powers of the IMFs that were calculated using signals from 06:10 to 06:25 a.m. LT on 9 August 2009. Note that the percentage powers of each IMF can change when different durations are chosen for the analysis. The percentage power of the fifth IMF (IMF 5) was 
$38.84 \%$ of the total spectrum power from the SGSB station, and it was the highest percentage power among the 14 SGSB IMFs that were calculated (Table 2). Although some small portion of the signals from the Shiaolin landslide is distributed in IMFs other than IMF 5, their influence is minimal. IMFs 1 through 3 at SGSB appear to represent noise, as shown in Fig. 7. There were also landslide-relevant signals in SGSB IMFs other than IMF 5, such as IMFs 4 and 6 (Fig. 7), that had similar signal patterns. IMFs 7 through 14 contained mostly noise but also may have contained some low frequency and/or aperiodic trend information; however, the percentage powers of IMFs 9 through 14 were quite low.

For the SGSB, the signals in IMF 5 were deemed the most representative of the seismic-wave patterns generated by the landslide. All of the IMFs could be used for the Hilbert transform; the amplitude-time-frequency Hilbert spectrum was obtained and is shown in Fig. 8a. During the landslide, a change in frequency over time can be observed. In Fig. 8a, the high spectral magnitudes distribute among 0.5 to $1.5 \mathrm{~Hz}$ and the energy from $1.5 \mathrm{~Hz}$ to $5 \mathrm{~Hz}$ is generally of lower frequency vibrations. Because IMF 5 from the SGSB station in Jiasian contained about $38.84 \%$ of the total energy and most of the noise was removed, it was worthwhile to check its Hilbert spectrum. Figure 8b shows the Hilbert spectrum of the SGSB IMF 5. High and certain very-low frequencies spectra were not seen in the Hilbert spectrum. The IMF 5; energy of the landslide signal was mainly distributed from 0.5 to $1.5 \mathrm{~Hz}$, as indicated by the Fourier transform of the SGSB IMF 5 that is shown in Fig. 9a.

For comparison, the percentage power and the Fourier transform of IMF 5 for the TPUB and TWMB stations were also calculated; they are shown in Table 2 and Figs. $9 \mathrm{~b}$ and c, respectively. Among the six stations analyzed, the TPUB station was the second closest to Shiaolin. The percentage power of IMF $5(44.93 \%)$ was the largest among the TPUB IMFs, which was similar to IMF 5 having the largest percentage power at the SGSB station. The frequency range of the TPUB IMF 5 was also from 0.5 to $1.5 \mathrm{~Hz}$ (Fig. 9b). Therefore, the TPUB IMF 5 and the frequencies from 0.5 to $1.5 \mathrm{~Hz}$ should be directly related to the Shiaolin landslide.

The distance from the TWMB station to the Shiaolin landslide was $44.4 \mathrm{~km}$, substantially farther than the distances from the SGSB and TPUB stations to the landslide. Therefore, the TWMB signals contained high levels of noise. The percentage power of the TWMB IMF 5 was only $0.9 \%$ (Table 2), and the percentage powers for many of the other TWMB IMFs were larger.

There may be an argument that the TWMB IMF 5 was not representative of the signals for the Shiaolin landslide. An examination of IMFs 1 through 14 from the TWMB station (Fig. 10) revealed that IMF 5 was the most relevant to the Shiaolin landslide, and the signal should not be identified as noise simply because of the low percentage power $(0.9 \%)$. Based on the signal pattern of IMF 4 shown in Fig. 10, the TWMB IMF 4 should also contain some signal from the
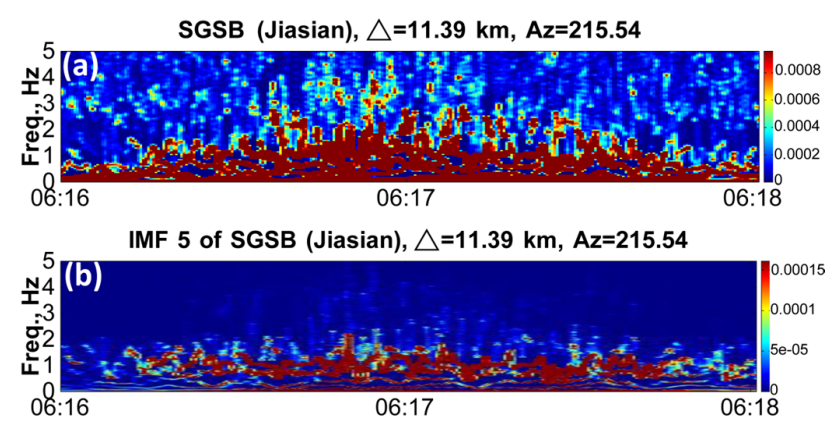

Fig. 8. (a) The SGSB amplitude-time-frequency Hilbert spectrum. (b) The amplitude-time-frequency Hilbert spectrum of the SGSB IMF 5.
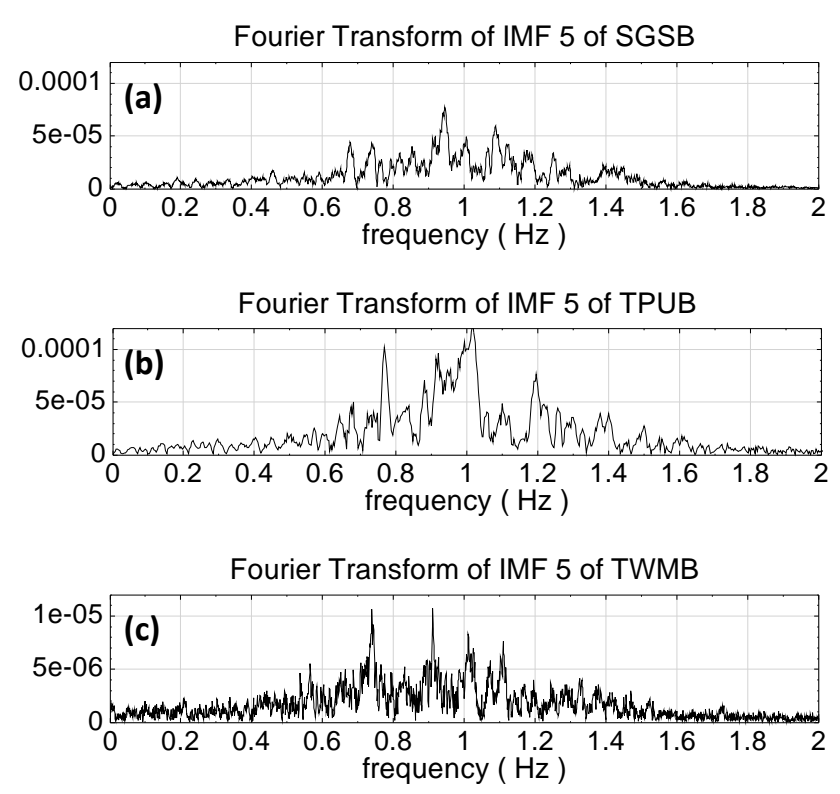

Fig. 9. The IMF 5 Fourier transform for stations (a) SGSB, (b) TPUB, and (c) TWMB.

landslide. IMFs 6 through 8 from the TWMB stations were difficult to identify as being related to the landslide, even though they contained significant percentage powers (particularly IMF 7, which contained $74.05 \%$ of the energy) (Table 2). Although the $0.9 \%$ power of the TWMB IMF 5 was small, the landslide signal could still be extracted by EMD. This result shows the power of EMD for analyzing nonlinear and nonstationary time series.

The frequency range of the TWMB IMF 5 was also from 0.5 to $1.5 \mathrm{~Hz}$ (Fig. 9c). In addition, the TWMB IMF 5 (Fig. 10) was similar in appearance to the SGSB waveform in Fig. 7.

For practical estimation, the TWMB, ELDB, ALSB, and WGKB IMF $5 \mathrm{~s}$ were considered to be characteristic of the Shiaolin landslide; however, SGSB IMFs 4 and 6 (Fig. 7) were used to assist in estimating the arrival times of the 

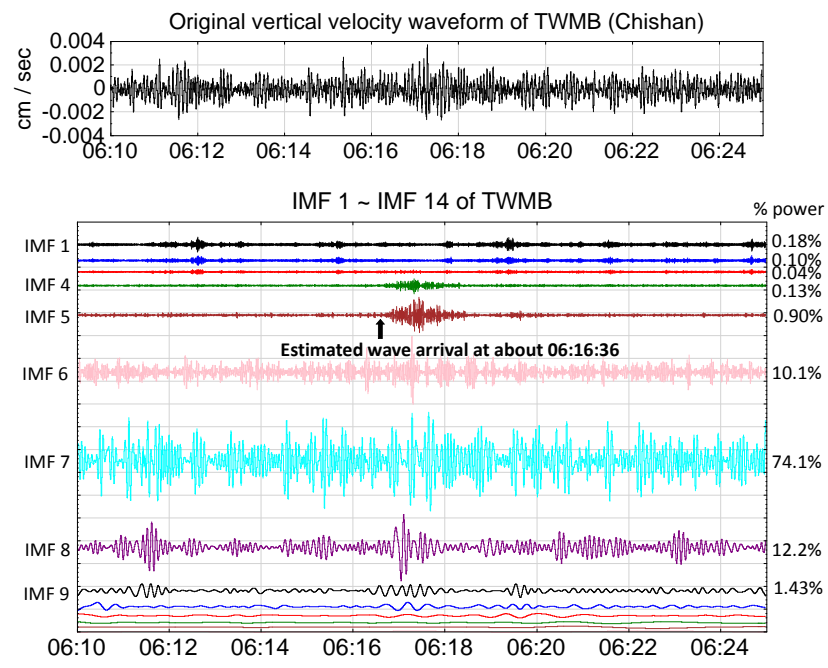

Fig. 10. IMFs 1-14 of the vertical velocity from the TWMB station (06:10 to 06:25 a.m. LT, 9 August 2009).

waves. The TWMB IMF 4 (Fig. 10) was also helpful for estimating the arrival time.

Based on the above discussion, the IMFs that contain high energy might have been noise, especially for stations that were located far from the landslide, such as TWMB, ALSB, and WGKB. For the closer stations, SGSB and TPUB, the energy was sufficient for identifying the landslide signals. For the more-distant stations, however, the frequency content was a better diagnostic because the frequencies generated by a landslide should be approximately constant and change minimally with wave propagation. The EMD is able to "sift" the signals from noise into the IMF frequency ranges, and the signals relevant to the landslide could be identified by visual observation of the IMF results, which demonstrates the usefulness and advantages of the EMD.

\subsection{The velocity of seismic waves induced by the landslide and the landslide origin time}

The two-minute-long ground-velocity seismic waveforms at the six stations from 06:16 to $06: 18$ on 9 August 2010 are shown in Fig. 11. The signals from the Shiaolin landslide at the SGSB and TPUB stations were easier to identify because the stations were closest to the landslide zone (11.39 and $15.3 \mathrm{~km}$, respectively). The maximum velocity was $0.01 \mathrm{~cm} \mathrm{~s}^{-1}$ at SGSB; however, the velocities at the four other stations quickly attenuated and fell below the noise level. It was therefore difficult to identify which portions of the signals at these stations were caused by the Shiaolin landslide. As shown in Fig. 12, IMF 5 was calculated for each of the signals in Fig. 11 using the EMD method. IMF 5 was chosen because the "sifted" waveforms showed less noise and could better represent the signals propagated from the Shiaolin landslide. In Fig. 12, the signals from the Shiaolin
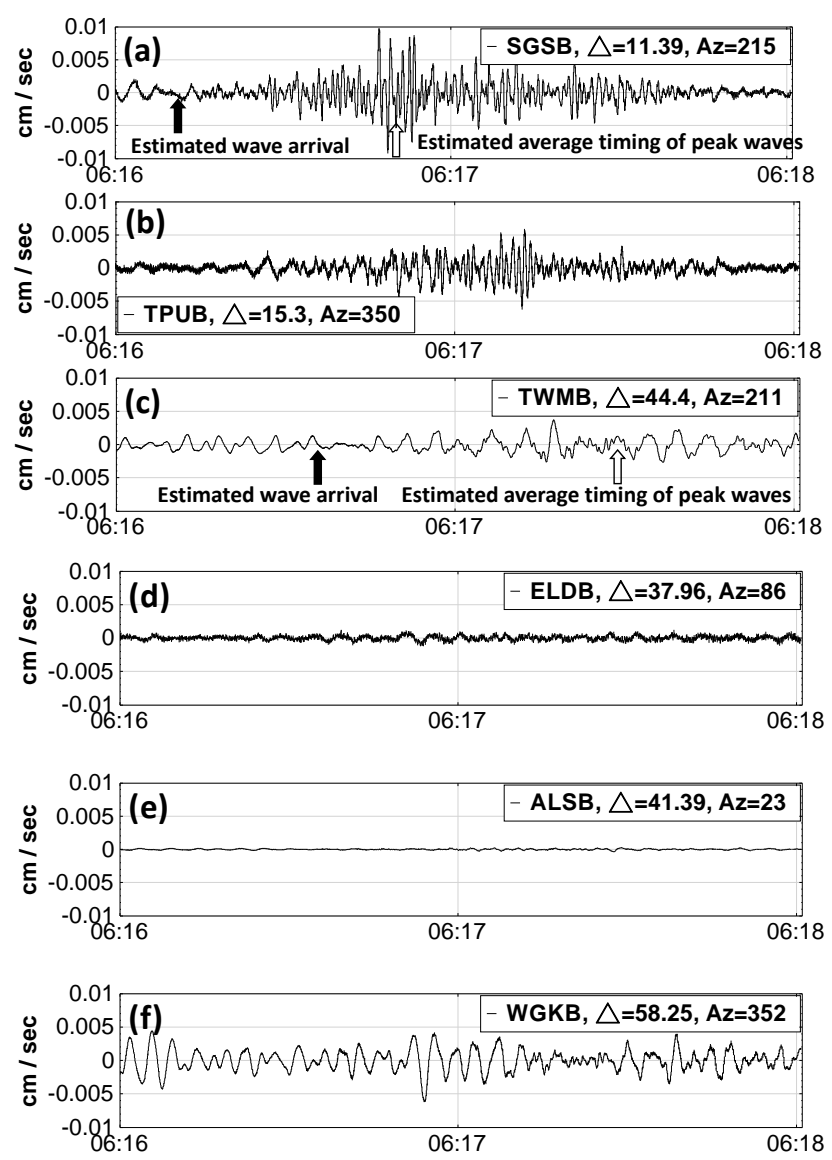

Fig. 11. The vertical velocity waveforms recorded by the six broadband stations.

landslide are reasonably "extracted" in IMF 5, as is discussed in Sect. 3.1. Even though the original signals at the TWMB, ELDB, ALSB, and WGKB stations in Fig. 11 contain high levels of noise, the signals related to the Shiaolin landslide are observable (Fig. 12). Therefore, only the IMF $5 \mathrm{~s}$ from the broadband stations were analyzed in this study.

The IMF 5 velocity amplitudes decayed quickly with increasing distance from the landslide origin and with increasing elevation. For example, the distances of the ELDB and ALSB stations from the landslide origin were about 38 and $41.4 \mathrm{~km}$, respectively, but the amplitudes of the ELDB and ALSB signals were much smaller than those of the TWMB signals $(44.4 \mathrm{~km})$ (Fig. 12). As shown in Fig. 3, the elevations of the ELDB and ALSB stations were higher (1040 and $2413 \mathrm{~m}$ above sea level, respectively) than Shiaolin, which caused the surface waves from the landslide to attenuate more quickly while traveling upward along the irregular topography. The landslide-induced seismic wave propagating through different geological conditions may also have caused the amplitudes of the ELDB and ALSB signals to attenuate more quickly. In general, high frequency waves should decay faster and very low frequency waves should travel farther and through deeper crust. 

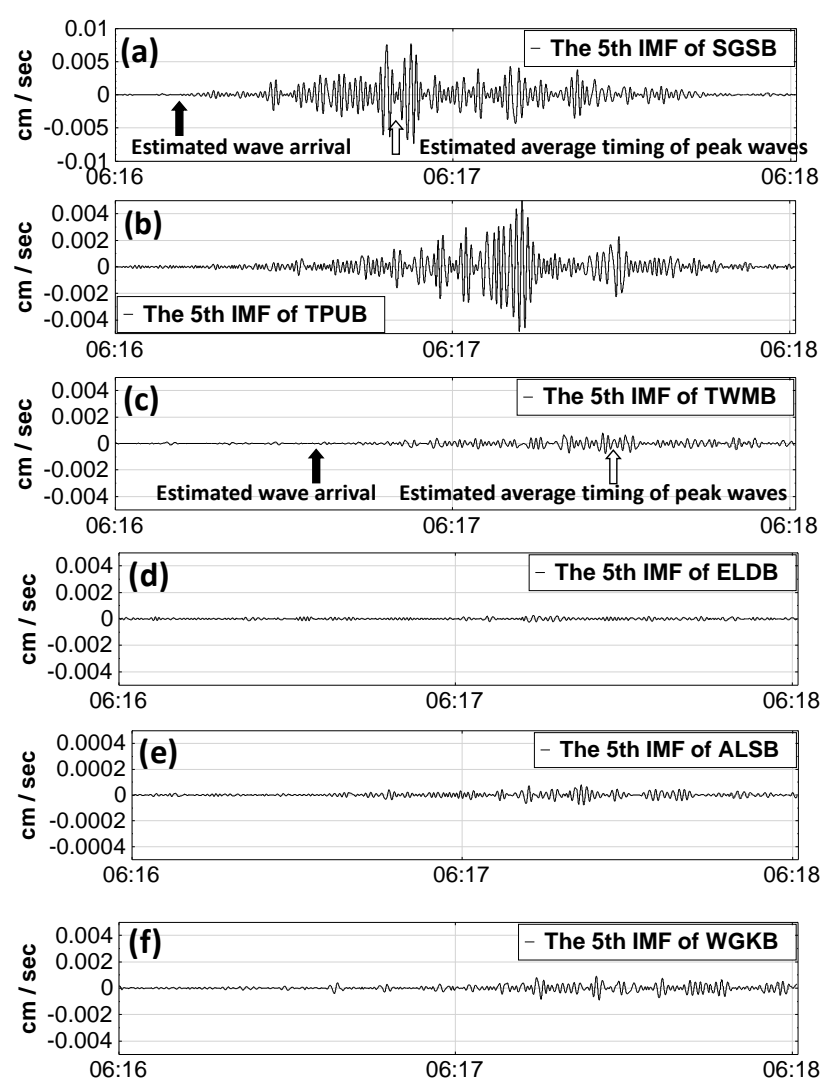

Fig. 12. The IMF 5 of the vertical velocity waveforms obtained from the EMD.

The SGSB and TWMB IMF 5 signals were chosen to estimate the velocities of the seismic waves and the origin time of the Shiaolin landslide because SGSB and TWMB form an approximate line with Shiaolin. The azimuths of Shiaolin to SGSB and TWMB are $215.54^{\circ}$ and $211.41^{\circ}$, respectively (Table 1). The strata in this area are assumed to be approximately linear and homogeneous, as explained in Sect. 2.2. The signal duration was approximately $98 \mathrm{~s}$, given that the vertical component of the wave arrived at the SGSB station at 06:16:11 and the coda continued until 06:17:49. The vertical component of the seismic wave arrived at the TWMB stations at approximately 06:16:36, and the coda ended at 06:18:30, making the signal duration approximately $114 \mathrm{sec}$. The estimated first-arrival times are indicated as solid arrows in Figs. 11 and 12. The first-arrival times correspond to the compressive P-waves. Therefore, the travel time of the P-waves between the SGSB and TWMB stations was $24.5 \pm 1 \mathrm{~s}$. The distance between the SGSB and TWMB stations is $33 \mathrm{~km}$; thus, the average propagation velocity of the $\mathrm{P}$-waves is estimated to be $1350 \pm 50 \mathrm{~m} \mathrm{~s}^{-1}$. The higheramplitude peaks in the SGSB and TWMB IMF $5 \mathrm{~s}$ were used for the approximate R-wave velocity. The average onset of these six to seven R-wave peaks was 06:16:50 for the SGSB station and 06:17:29 for the TWMB station, as indicated by
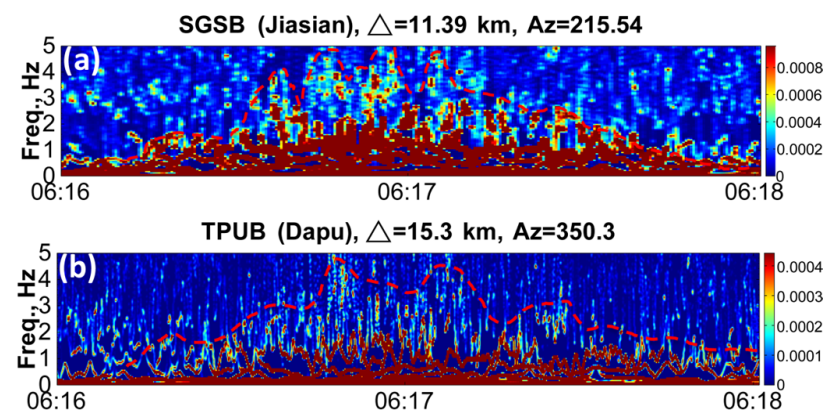

TWMB (Chishan), $\triangle=44.4 \mathrm{~km}, \mathrm{AZ}=\mathbf{2 1 1 . 4 1}$

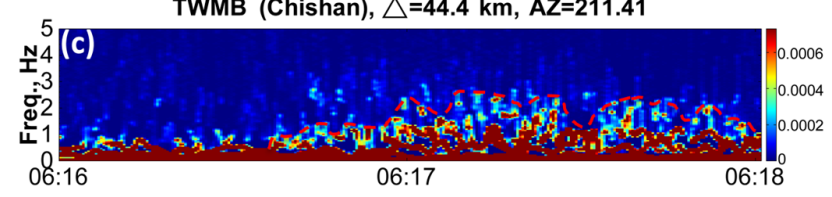

ELDB (Lidao), $\triangle=37.96 \mathrm{~km}, \mathrm{Az}=86.26$

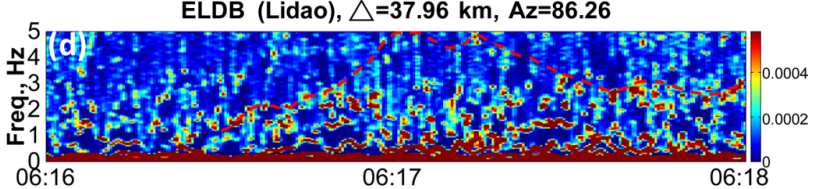

ALSB (Alishan), $\triangle=41.39 \mathrm{~km}, \mathrm{Az}=\mathbf{2 3 . 1 2}$

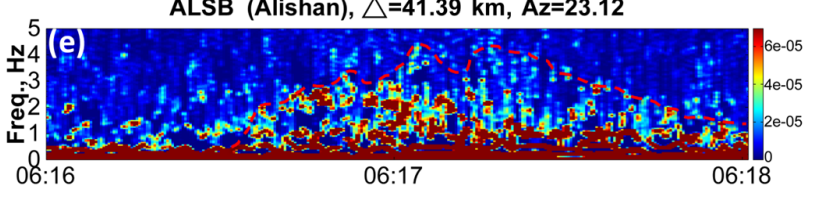

WGKB (Gukeng), $\triangle=58.25 \mathrm{~km}, \mathrm{Az}=351.59$

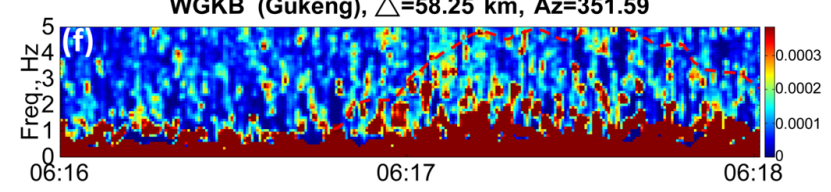

Fig. 13. The HHT time-frequency spectra of the six seismic stations. The red dashed lines encircle the most significant spectra ranges for the Shiaolin landslide.

the open arrows in Fig. 12. Based on the open arrows in Fig. 11, the average timing of these R-wave peaks is not as easy to identify from the original TWMB signal as from the TWMB IMF 5 (Fig. 12). The approximate travel time of the R-wave between the SGSB and TWMB stations was $38.8 \pm 0.5 \mathrm{~s}$. Using the $33-\mathrm{km}$ distance between the two stations, the propagation velocity of the R-wave was approximately $850 \pm 10 \mathrm{~m} \mathrm{~s}^{-1}$.

These two average velocities, $1350 \mathrm{~m} \mathrm{~s}^{-1}$ and $850 \mathrm{~m} \mathrm{~s}^{-1}$, are reasonable for P-waves and R-waves, respectively, traveling along a relatively shallow crustal path $(<500 \mathrm{~m}$ depth) in the sedimentary strata of this region. They are much slower than the $4000 \mathrm{~m} \mathrm{~s}^{-1} \mathrm{P}$-wave velocity of the Shiaolin landslide event that was deduced from the long-period signals in Lin et al. (2010). It is because the long-period waves were traveling at greater depths and their velocities are much faster than those of waves traveling in shallow depths. Furthermore, the two estimated average velocities were calculated 

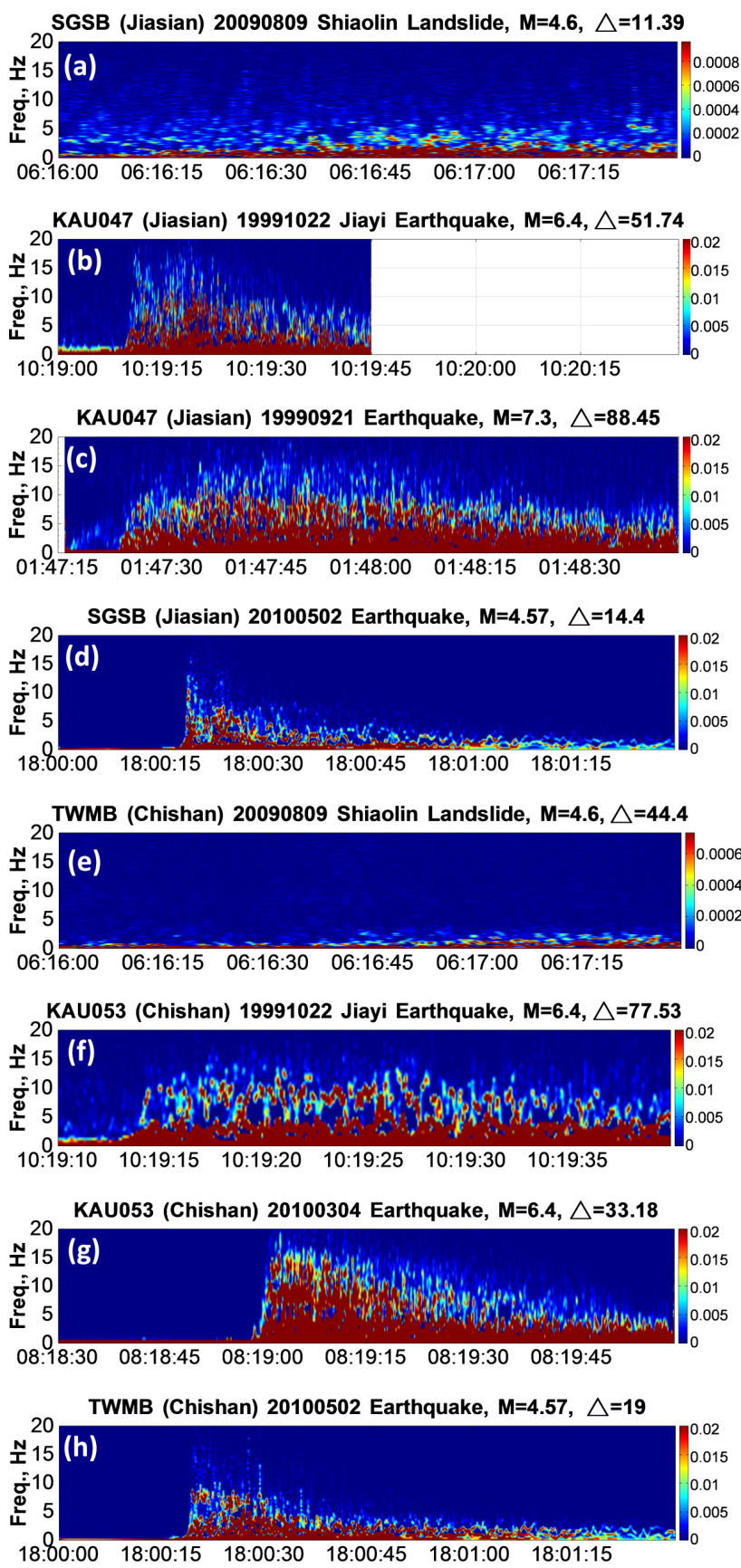

Fig. 14. The HHT time-frequency spectra of the earthquakes recorded at the Jiasian and Chishan free-field strong-motion and broadband stations. ( $M$ : Richter scale magnitude.)

from the short-period signals $(0.5$ to $1.5 \mathrm{~Hz}$ ) shifted by EMD and the long-period signals were mostly excluded, thus they could represent the slower velocities of surface waves traveling in shallower depths.

The 114-s duration of the landslide signals at the TWMB station was longer than the 98-s duration measured at the SGSB station. This behavior was the result of the wave prop- agation dispersion phenomenon that causes waves of different frequencies to travel at different velocities (Deparis et al., 2008). The distance from Shiaolin to SGSB is $11.39 \mathrm{~km}$, and the landslide-induced $\mathrm{P}$-waves should have taken approximately $8 \mathrm{~s}$ to travel this distance in shallow earth surface. Therefore, the origin time of the Shiaolin landslide was estimated to be 06:16:03 on 9 August 2009. These estimates are close to the calculations determined by Tsou et al. (2011) that were obtained using the IMF $5 \mathrm{~s}$ of $\mathrm{N}-\mathrm{S}$ components from SGSB and TWMB stations.

\subsection{Time-frequency spectra}

The HHT spectra for the six stations are shown in Fig. 13. To aid in visual inspection of the spectra, the red dashed lines encircle the most significant spectra ranges for the Shiaolin landslide. The landslide's time-frequency spectra from the closest station (SGSB) are predominantly between 0.5 to $5 \mathrm{~Hz}$ (encircled by the red dashed line) and last approximately $98 \mathrm{~s}$, as was mentioned previously. The successively larger impacts from the Shiaolin landslide show larger spectral magnitudes and higher frequency content. The frequencies below $0.5 \mathrm{~Hz}$ contain high noise levels. The significant frequencies related to the Shiaolin landslide are between 0.5 and $1.5 \mathrm{~Hz}$, as determined from the Fourier transform of the SGSB IMF 5. The HHT spectra of the other five stations also show spectral magnitudes that belong to the Shiaolin landslide event, although they contain more noise. Some spectra are difficult to identify as being related to the Shiaolin landslide, such as those from the ELDB and WGKB stations (Figs. 13d and f).

\subsection{A spectral comparison between the landslide and earthquakes}

The time-frequency spectra obtained by the HHT for the vertical signals of three earthquakes recorded at the Jiasian and Chishan free-field strong-motion stations are shown in Fig. 14, along with the Shiaolin landslide spectrum for comparison. There were high-frequency responses in the spectra of the earthquakes, with frequencies as high as $17 \mathrm{~Hz}$. The closer the station was to the epicenter, the stronger the highfrequency components of the spectra were. For comparison, the 2 May $2010 M_{\mathrm{S}}=4.57$ earthquake near the SGSB and TWMB stations was also analyzed, as shown in Figs. 14d and $h$. Due to a magnitude that was smaller than those of the 21 September 1999, 22 October 1999, and 4 March 2010 earthquakes, the high-frequency content of the 2 May 2010 earthquake was smaller, although the epicenter of the 2 May 2010 earthquake was closer to Jiasian and Chishan. However, the frequency contents for the 2 May $2010 M_{\mathrm{s}}=4.57$ earthquake at the two stations were still higher than those for the Shiaolin landslide, even though the magnitudes of the 2 May 2010 earthquake and the Shiaolin landslide were similar. 
The main frequency range of the Shiaolin landslide fell between 0.5 and $1.5 \mathrm{~Hz}$ (Figs. 13 and 14), which was much smaller than those of the earthquakes in question. The deepseated landslide mass could only produce a few heavy impacts per second during the sliding, rolling, and rebounding on the failure surfaces.

\subsection{The potential application of the SASW method to characterize the shear velocity of strata}

A potential application of the spectral analysis of surface waves (SASW) method (Nazarian et al., 1983) is proposed to characterize the surface shear-wave velocity of the regional strata between Jiasian and Chishan to a depth of approximately $10 \mathrm{~km}$. This method may be applied because Shiaolin, Jiasian, and Chishan are located in the same geological unit, they form an approximate straight line (Fig. 2), and their elevations are similar (Fig. 3). The SGSB and TWMB IMF $5 \mathrm{~s}$ (Figs. 12a and $\mathrm{b}$ ) can be selected for this purpose; however, because the TWMB IMF 5 still contains noise and may not contain most of the surface seismic signals after the EMD, the surface shear wave velocity obtained by the SASW method is not of high quality. Although the Shiaolin landslide provided a rare opportunity to apply the SASW method, the Shiaolin landslide produced more than one significant impact, limiting the use of the SASW method. If the geographic requirements for using the SASW method are met and the seismic signals of a near vertical free-fall event can be acquired (the rockfall events of Yosemite Valley, California are a good example of this type of event; Stock and Uhrhammer, 2010), the SASW method should be successfully applied.

\section{Summary and conclusions}

The Shiaolin landslide occurred on 9 August 2009 and produced seismic signals. The signals recorded by six broadband stations were analyzed to understand the seismic signals caused by the landslide. The timing of the landslide event was resolved using the EMD. The time-frequency spectra obtained by the Hilbert-Huang Transform (HHT) clearly showed the landslide event and frequency contents of the signals. The EMD was successfully used to separate the weak surface wave signals induced by the Shiaolin landslide from the background noise. Most of the signal from the Shiaolin landslide was distributed in the fifth intrinsic mode function (IMF 5). The average velocities of the surface waves in the region's shallow strata could then be approximately quantified using IMF $5 \mathrm{~s}$ from the SGSB and TWMB stations. The $0.5 \mathrm{~Hz}$ to $1.5 \mathrm{~Hz}$ frequency range was identified in IMF 5 of the Shiaolin landslide seismic waves. This range was smaller than those produced by the other earthquakes that were also analyzed. Finally, the potential application of the SASW method to characterize the shear velocity of the strata in the region was suggested. Analyzing and understanding the seismic signatures of the Shiaolin landslide should provide a great opportunity for further large-scale landslide research.

Acknowledgements. The support of the National Science Foundation of Taiwan (97-2313-B-005-042-MY3) was greatly appreciated. The author acknowledges the Central Weather Bureau and Academia Sinica, Taiwan for providing the broadband seismic data and the Water Resources Agency, MOEA, of Taiwan for providing the Jiasian precipitation data (COV250) and the Shanlin stream water-level data $(1730 \mathrm{H} 058)$. The author is grateful to the referees, whose comments improved the paper.

Edited by: T. Glade

Reviewed by: two anonymous referees

\section{References}

AnCAD, Inc.: Visual Signal Reference Guide, Version1.3, AnCAD, Inc, 2010 (in Chinese).

Berrocal, J., Espinosa, A. F., and Galdos, J.: Seismological and Geological Aspects of Mantaro Landslide in Peru, Nature, 275, 5680, 533-536, 1978.

Central Geological Survey: The geological investigation report of the March 4th, 2010 Earthquake, http://fault.moeacgs. gov.tw/TaiwanFaults/PageContent.aspx?type $=\mathrm{C} \backslash \& \mathrm{id}=185$, accessed: 10 June 2010 (in Chinese).

Chen, P.-T. and Liu, Y.-C.: The investigation report of the active faults - The Chishan fault, Central Geological Survey, Ministry of Economic Affairs, Taiwan, 2006 (in Chinese).

Chen, S.-C. and Wu, C.-H.: The Geomorphological Variation Triggered by Catastrophic Deep Landslide in Siaolin Village, Journal of Chinese Soil and Water Conservation, 40, 4, 359-376, 2009a (in Chinese).

Chen, S.-C. and Wu, C.-H.: The Formation and Failure of Typhoon Morakot-Triggered Landslide Dam in Siaolin Village, Journal of Chinese Soil and Water Conservation, 40, 4, 377-392, 2009b (in Chinese).

Crockett, R. G. M. and Gillmore, G. K.: Spectral-decomposition techniques for the identification of radon anomalies temporally associated with earthquakes occurring in the UK in 2002 and 2008, Nat. Hazards Earth Syst. Sci., 10, 1079-1084, doi:10.5194/nhess-10-1079-2010, 2010.

Crockett, R. G. M., Perrier, F., and Richon, P.: Spectraldecomposition techniques for the identification of periodic and anomalous phenomena in radon time-series, Nat. Hazards Earth Syst. Sci., 10, 559-564, doi:10.5194/nhess-10-559-2010, 2010.

De Angelis, S., Bass, V., Hards, V., and Ryan, G.: Seismic characterization of pyroclastic flow activity at Soufrire Hills Volcano, Montserrat, 8 January 2007, Nat. Hazards Earth Syst. Sci., 7, 467-472, doi:10.5194/nhess-7-467-2007, 2007.

Deparis, J., Jongmans, D., Cotton, F., Baillet, L., Thouvenot, F. and Hantz, D.: Analysis of Rock-Fall and Rock-Fall Avalanche Seismograms in the French Alps, B. Seismol. Soc. Am., 98, 4, 1781-1796, doi:10.1785/0120070082, 2008.

Feng, Z.-Y.: The seismic signatures of the surge wave from the 2009 Xiaolin landslide-dam breach in Taiwan, manuscript, Hydrol. Process., submitted, 2011. 
Huang, N. E., Shen, Z., Long, S. R., Wu, M. C., Shih, H. H., Zheng, Q., Yen, N. C., Tung, C. C., and Liu, H. H.: The empirical mode decomposition and the Hilbert spectrum for nonlinear and nonstationary time series analysis, in: Proceedings of the royal society of London, series a: mathematical, Physical and Engineering Sciences, 454, 903-995, 1998.

Huang, N. E. and Wu, Z. H.: A review on Hilbert-Huang transform: Method and its applications to geophysical studies, Rev. Geophys., 46, 2, 1-23, 2008.

Keng, W.-P.: Geology of the Chiahsien-Chishan Area, Southern Taiwan, Bulletin of the Geological Survey of Taiwan, 19, Central Geological Survey, Ministry of Economic Affairs, Taiwan, 8 pp., 1967.

Lin, C. H., Kumagai, H., Ando, M., and Shin, T. C.: Detection of landslides and submarine slumps using broadband seismic networks, Geophys. Res. Lett., 37, L22309, doi:10.1029/2010g1044685, 2010.

Nazarian, S., Stokoe II, K. H., and Hudson, W. R.: Use of spectral analysis of surface waves method for determination of moduli and thickness of pavement systems, Transportation Research Records, 930, 38-45, 1983.
Stock, G. M. and Uhrhammer, R. A: Catastrophic Rock Avalanches 3600 Years BP from El Capitan, Yosemite Valley, California, Earth Surf. Proc. Land., 35, 941-951, 2010.

Suriñach, E., Vilajosana, I., Khazaradze, G., Biescas, B., Furdada, G., and Vilaplana, J. M.: Seismic detection and characterization of landslides and other mass movements, Nat. Hazards Earth Syst. Sci., 5, 791-798, doi:10.5194/nhess-5-791-2005, 2005.

Tsai, F., Hwang, J.-H., Chen, L.-C., and Lin, T.-H.: Post-disaster assessment of landslides in southern Taiwan after 2009 Typhoon Morakot using remote sensing and spatial analysis, Nat. Hazards Earth Syst. Sci., 10, 2179-2190, doi:10.5194/nhess-10-21792010, 2010.

Tsou, C. Y., Feng, Z. Y., and Chigira, M.: Catastrophic landslide induced by Typhoon Morakot, Shiaolin, Taiwan, Geomorphology, 127, 166-178, doi:10.1016/j.geomorph.2010.12.013, 2011.

Vilajosana, I., Suriñach, E., Abellán, A., Khazaradze, G., Garcia, D., and Llosa, J.: Rockfall induced seismic signals: case study in Montserrat, Catalonia, Nat. Hazards Earth Syst. Sci., 8, 805-812, doi:10.5194/nhess-8-805-2008, 2008. 